\title{
Cutaneous manifestations in COVID-19 - clinical forms and differential diagnosis
}

\author{
Manifestări cutanate în COVID-19 - forme clinice și diagnostic diferențial
}

\author{
Polliana Mihaela LERU ${ }^{1,2}$, Iulia Elena NEGULET ${ }^{1}$, Vlad Florin ANTON ${ }^{1}$, \\ Mihaela Daniela BALTĂ ${ }^{2}$ \\ ${ }^{1}$ Spitalul Clinic Colentina, București, România \\ 2Universitatea de Medicină și Farmacie „Carol Davila“, București, România
}

\begin{abstract}
Infection with the new coronavirus SARS-CoV-2, responsible for COVID-19 disease, may occur differently from person to person. The main symptoms of SARS-CoV-2 virus infection are dry cough, dyspnea, fever and fatigue. In addition, other symptoms that occur less frequently in COVID-19 disease have been described, such as: headache, diarrhea, muscle aches, conjunctivitis and skin manifestations. The cutaneous manifestations appeared in this disease are mainly represented by the morbiliform rash, urticaria, COVID fingers and less often vesicular eruptions and livedo reticularis. These skin lesions are also found in other diseases and can cause problems of differential diagnosis, especially in the case of adverse drug reactions.
\end{abstract}

Keywords: COVID-19, SARS-CoV-2, skin manifestation, adverse drug reactions

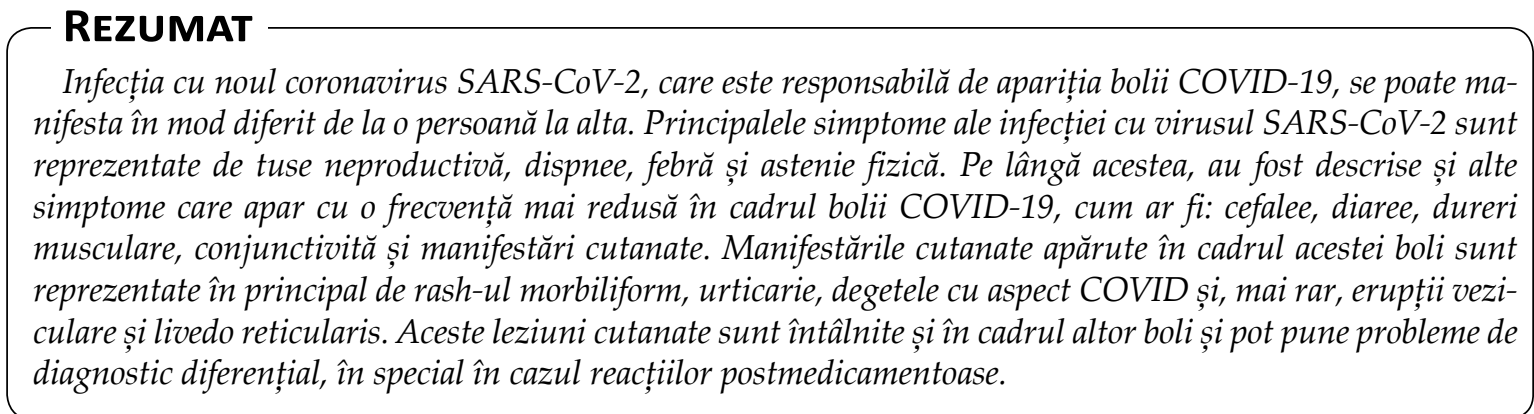

Cuvinte cheie: COVID-19, SARS-CoV-2, manifestări cutanate, reacții postmedicamentoase

\section{INTRODUCERE}

Pandemia declarată de către Organizația Mondială a Sănătății în martie 2020, produsă de noul coronavirus, numit SARS-CoV-2, a adus în fața comunității medicale o patologie extrem de polimorfă, cu evoluție imprevizibilă și grade diferite de severitate.
Simptomatologia COVID-19 variază de la pacienți complet asimptomatici la sindrom de detresă respiratorie acută și sindromul de disfuncție multiplă de organe (1). Cele mai frecvente simptome sunt reprezentate de febră, tuse, dispnee, dar și simptome precum dureri în gât, dureri musculare, greață, diaree, anosmie, ageuzie au fost întâlnite la pacienții diagnosticați cu 
COVID-19 (2). Un studiu recent efectuat pe 1.600 pacienți cu COVID-19 a identificat șase tipuri de asocieri de simptome (clusters) în cadrul bolii: tipul gripal fără febră, gripal cu febră, gastro-intestinal și trei forme severe, evaluate în funcție de gradul asteniei, dispneei, confuziei și simptomelor digestive plus respiratorii.

Au fost observate și manifestări cutanate la o serie de pacienți, asemănătoare cu cele provocate de infecțiile virale comune, dar și unele forme particulare, considerate caracteristice acestei boli (3).

\section{MECANISME DE ACȚIUNE}

Virusul pătrunde în organism la nivelul mucoasei respiratorii, prin intermediul receptorului enzimei de conversie a angiontensinei II - tractul respirator fiind principalul loc de acțiune (1). Acesta este capabil să producă o reacție imună exagerată din partea gazdei, în unele cazuri fiind descrisă o „furtună citokinică“, care duce la o deteriorare semnificativă a țesuturilor (4).

Privitor la mecanismele de acțiune ale virusului SARS-CoV-2 la nivelul pielii, acestea nu au fost pe deplin elucidate, dar sunt avute în vedere câteva teorii. Particulele virale prezente în vasele de sânge pot duce la o vasculită limfocitară prin intermediul complexelor imune circulante, care activează citokinele. Keratinocitele pot fi afectate secundar, după afectarea celulelor Langerhans.

Conform unor teorii, livedo reticularis, una dintre cele mai frecvente manifestări cutanate, este consecința acumulării microtrombilor formați la nivelul altor organe, care migrează și se acumulează la nivelul microcirculației cutanate.

Încă este neclar dacă apariția unor manifestări cutanate în cadrul COVID-19 este consecința afectării pulmonare sau acestea apar în urma unei leziuni primare determinate de virus la nivelul pielii (3).

\section{FORME CLINICE}

Primele studii efectuate în China au raportat manifestări cutanate la pacienții infectați cu virusul SARS-CoV-2 într-o proporție mică, de 0,2\% (5), însă în prezent sunt întâlnite din ce în ce mai des (6).

În funcție de frecvența de apariție a acestora, s-au descris: rash-ul morbiliform (49\%), erupții urticariene (19\%), degetele COVID (19\%), erupții veziculare (9\%), livedo reticularis (6\%) (7).

Majoritatea leziunilor au fost localizate la nivelul trunchiului $(66,7 \%)$, însă la un procent mic de pacienți (19\%) au fost observate manifestări cutanate la nivelul mâinilor și picioarelor.

Severitatea leziunilor variază de la degetele COVID, considerate leziuni cu grad de severitate mic, la livedo reticularis, care este considerată afectare severă (8).

\section{Urticaria}

Infecțiile reprezintă una dintre cauzele frecvent întâlnite în urticarie, aceasta fiind descrisă și în cadrul bolii COVID-19.

Leziunile cutanate sunt situate în general la nivelul trunchiului și nu au fost asociate cu gravitatea bolii, fiind însoțite sau nu de febră (3).

\section{Rash-ul morbilliform}

La o serie de pacienți, a fost întâlnit rash-ul morbilliform, localizat predominant la nivelul trunchiului. Acesta a apărut la debutul bolii, dar a fost observat frecvent și la externarea pacienților.

\section{Erupţiile veziculare}

În cadrul COVID-19, au fost descrise mici vezicule asemănătoare celor din varicelă (11). Erupțiile veziculare au fost fie monomorfe, localizate la nivelul trunchiului, fie polimorfe, localizate difuz. De obicei, au

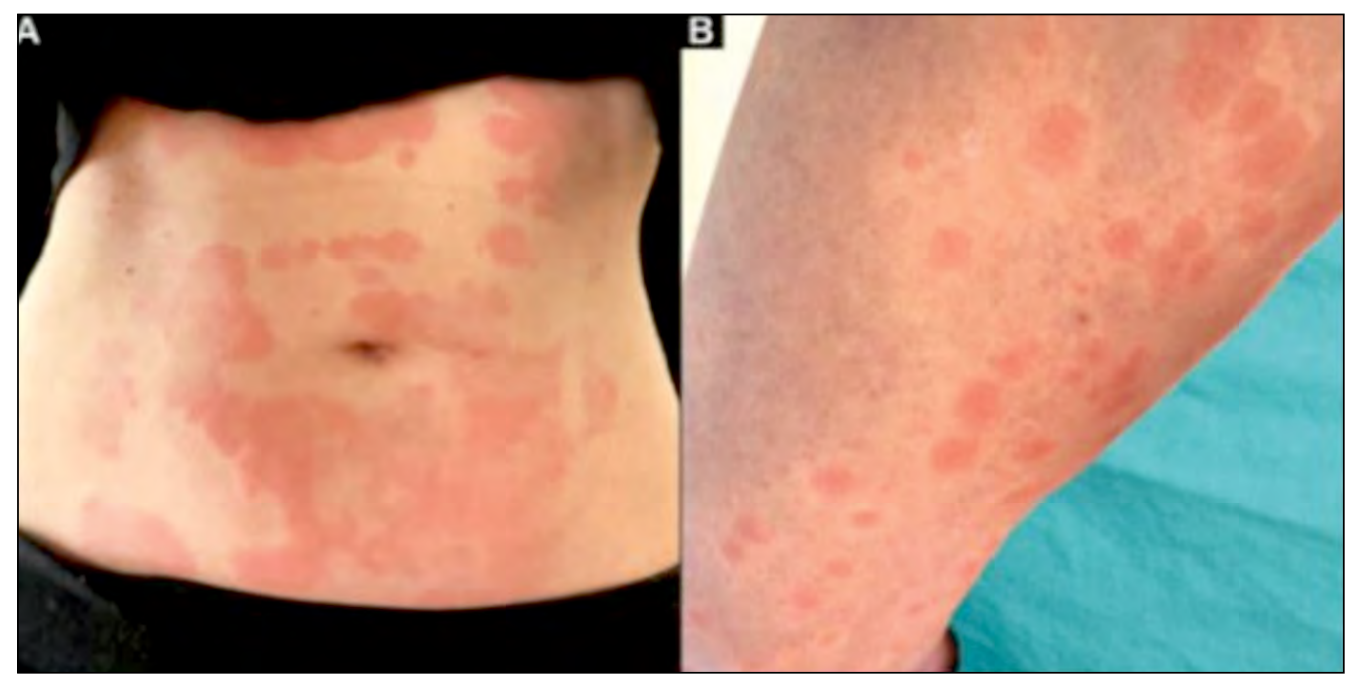

FIGURA 1. Erupție urticariană localizată la nivelul (A) trunchiului și (B) coapsei. Pacientă în vârstă de 39 de ani, cu leziuni urticariene care au apărut la o zi după apariția anosmiei și înaintea apariției febrei (9) 


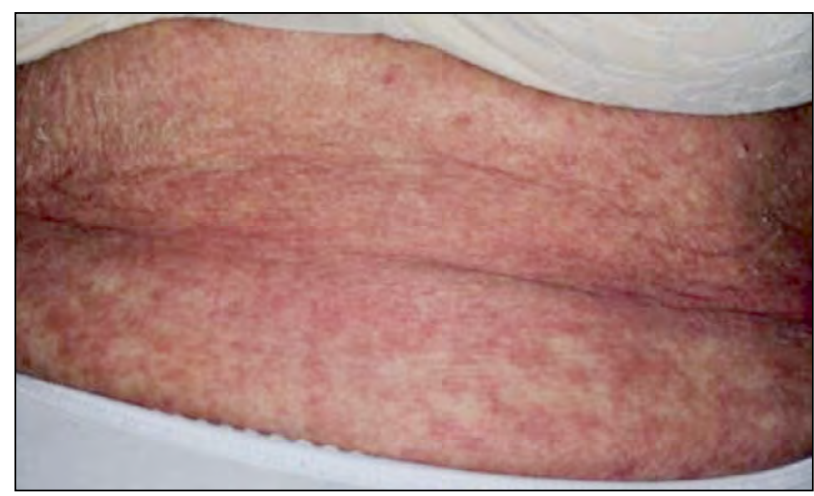

FIGURA 2. Rash morbiliform (10)

apărut după debutul simptomelor tipice de boală, dar au fost observate și cazuri în care leziunile cutanate au apărut înaintea lor (12).

În urma biopsiei cutanate, au fost descrise caracteristici similare cu cele găsite în exantemele virale (9). De asemenea, pentru un număr mic de pacienți au fost efectuate teste RT-PCR pentru SARS-CoV-2 din lichidul vezicular, cu rezultate negative (11).

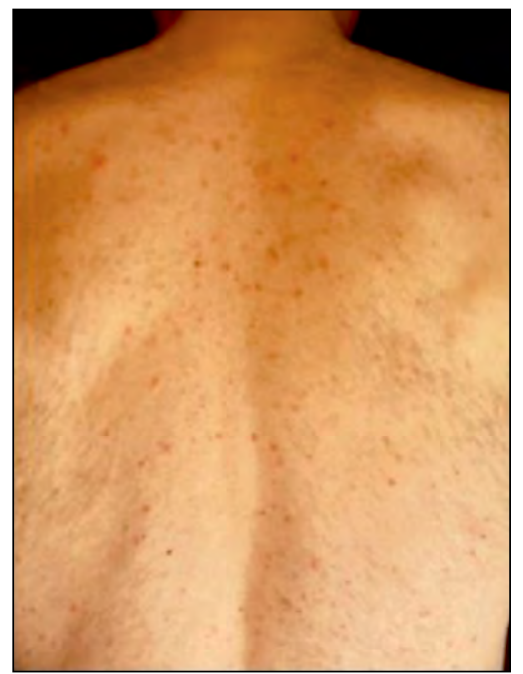

FIGURA 3. Erupție veziculară monomorfă, diseminată, localizată la nivelul trunchiului (8)

\section{Degetele COVID}

La un număr mare de pacienți, în special la adolescenți și adulți tineri, a fost semnalată prezența unor macule sau papule roșii-violacee, însoțite sau nu de prurit și/sau edem $(13,14)$. Acestea sunt localizate la nivelul degetelor mâinii, dar mai ales la degetele de la picioare (8), și sunt asemănătoare cu cele întâlnite în cazul degerăturilor, fiind numite degetele COVID. Acești pacienți au avut testul RT-PCR pentru virusul SARSCoV-2 negativ, însă testele serologice au identificat anticorpii IgM și IgG anti-SARS-CoV-2; ceea ce arată faptul că apar mai tardiv în cursul evoluției bolii (11).

Histopatologic, s-au descris un infiltrat limfoid dens, difuz, localizat la nivelul dermului superficial, dermului profund și hipodermului, și semne de activare endotelială (14).

\section{Livedo reticularis}

Este o anomalie vasculară caracterizată printr-o modificare de culoare a pielii, căpătând un aspect marmorat. Poate fi asociat cu ischemia progresivă cu sau fără prezența unei boli sistemice (3).

În COVID-19 au fost descrise manifestări cutanate similare cu livedo reticularis (9), observate mai frecvent la pacienți în vârstă cu multiple comorbidități, având un prognostic mai prost (7).

Examenul histopatologic a pus în evidență o vasculopatie, iar analizele de laborator au arătat modificări de coagulare la pacienți cu COVID-19 formă severă și ischemie la nivelul membrelor inferioare (11).

\section{DIAGNOSTIC DIFERENȚIAL}

Principalul diagnostic diferențial al erupțiilor cutanate poate fi făcut cu reacțiile cutanate date de ingestia de medicamente. Reacțiile adverse cutanate date de antiinflamatoarele nonsteroidiene sunt cel mai co-

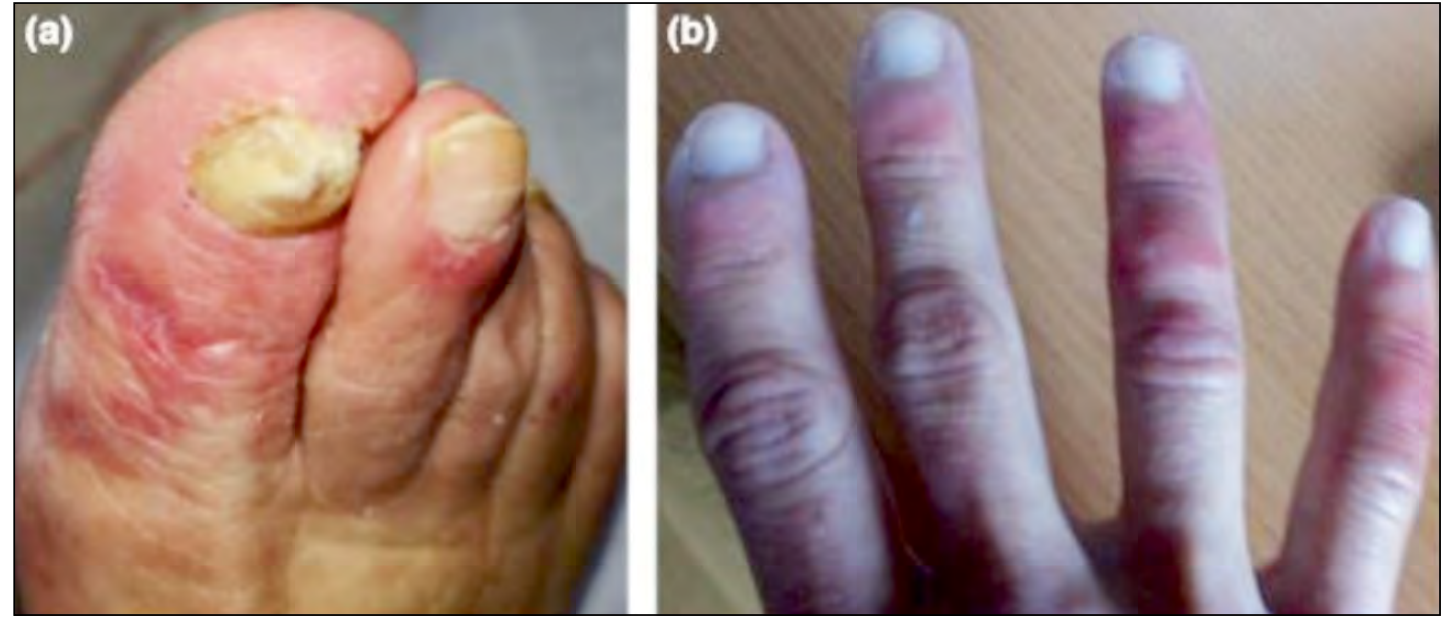

FIGURA 4. Degete COVID şi livedo reticularis (7) 


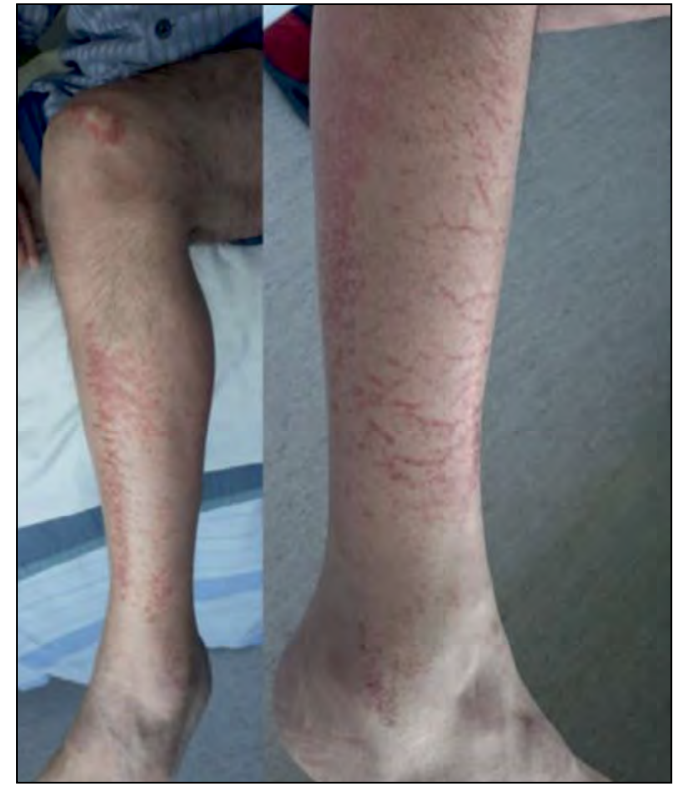

FIGURA 5. Livedo reticularis (15)

mun întâlnite, având o frecvență de 0,02-0,7\% în populația generală (16).

Angioedemul și urticaria sunt cel mai des observate și apar în general după ingestia de ibuprofen. A doua cel mai frecvent întâlnită reacție adversă cutanată este reprezentată de rash-ul maculo-papular, observat frecvent după administrarea de celecoxib. Au fost descrise rar sindromul Steven-Johnson și necroliza toxică epidermică (17).

Medicația antivirală administrată în infecția cu virusul SARS-CoV-2 poate da o serie de reacții adverse cutanate care pot fi similare cu leziunile cutanate induse de acest virus.

Remdesivir, un antiviral folosit în infecția cu virusul SARS-CoV-2, la care a fost observată inhibarea replicării virale prin blocarea ARN-polimerazei, poate determina și el reacții adverse cutanate, cum ar fi rash-ul urticarian. Alte antivirale studiate pentru tratamentul COVID-19 dau și ele manfestări cutanate precum rash, angioedem, sindrom Steven-Johnson, necroliză toxică epidermică, diverse vasculopatii (18).

Rash-ul urticarian și rash-ul morbiliform trebuie diferențiate de exantemele apărute în cadrul infecțiilor virale comune (8). Erupția veziculară poate fi similară cu cea descrisă în varicelă și trebuie avută în vedere în cadrul diagnosticului diferențial (3).

\section{REACȚII POSTMEDICAMENTOASE}

O parte dintre medicamentele care au fost considerate eficiente în tratamentul COVID-19 pot determina reacții adverse cutanate.

Clorochina și hidroxiclorochina prezintă in vitro activitate antivirală împotriva COVID-19 (15). Acestea induc relativ frecvent erupție morbiliformă, hiperpigmentare și prurit. Rar, poate apărea sindromul StevenJohnson (9).

În combinație cu hidroxiclorochina, azitromicina a avut rezultate bune împotriva COVID-19 (15). Reacțiile adverse cutanate observate la ingestia de azitromicină au fost: erupție morbiliformă și, de asemenea, un rash urticarian. Rar, poate apărea și sindromul StevenJohnson (9).

Corticosteroizii au proprietăți antiinflamatoare, suprimând inflamația produsă în contextul COVID-19. Aceștia pot induce la rândul lor prurit, erupții urticariene, eritem, edem.

Tocilizumab este un anticorp monoclonal împotriva receptorului IL-6, având efect asupra „, furtunii citokinice" descrise în cadrul infecției cu virusul SARS-CoV-2 (15). Reacții adverse cutanate rare au fost descrise și în cazul acestuia, cum sunt: erupția papulo-pustuloasă, dermatita psoriaziformă și sindromul Steven-Johnson (9).

Evaluarea reacțiilor postmedicamentoase în practica medicală este în general dificilă, cu atât mai mult în contextul infecțios viral, și necesită cunoașterea principiilor de diagnostic conform ghidurilor actuale și consultul alergologic de specialitate $(19,20)$. Există și situații în care se pot asocia cauze multiple, ceea ce impune monitorizarea atentă, tratament simptomatic și întreruperea medicației posibil incriminate.

\section{CONCLUZII}

Incidența manifestărilor cutanate în COVID-19 este în creștere, iar caracterul polimorf al leziunilor și asocierea altor semne și simptome va permite o evaluare mai riguroasă, în dinamică a acestora, posibil și identificarea unor factori predispozanți.

Prognosticul leziunilor cutanate din COVID-19 este variabil și, până în prezent, nu se cunoaște cu certitudine, dar unele forme, cum este livedo reticularis, se pot asocia cu evoluție mai severă a bolii.

Conflict of interest: none declared Financial support: none declared 


\section{BIBLIOGRAFIE}

1. Singhal T. A Review of Coronavirus Disease-2019 (COVID-19). Indian J Pediat. 2020;87(4):281-286.

2. Ouassou $H$, Kharchouf $L$, Bouhri M, et al. The Pathogenesis of Coronavirus Disease 2019 (COVID-19): Evaluation and Prevention. J Immunol Res. 2020.

3. Elmas Ö, Demirba F, Özyurt A et al. Cutaneous manifestations of COVID-19: A review of the published literature. Dermatol Ther. 2020

4. Tezer H, Demirag TB. Novel coronavirus disease (COVID-19) in children. Turk J Med Sci. 2020;21;50(SI-1):592-603.

5. Wollina W, Karadag A, Rowland-Payne S et al. Cutaneous signs in COVID-19 patients: A review. Dermatol Ther. 2020.

6. Khalid H. Urticaria and angioedema as a prodromal cutaneous manifestation of SARS-CoV-2 (COVID-19) infection. BMJ Case Rep. 2020;13(7):e236981.

7. Galvaan Casas C, Catala A et al. Classification of the cutaneous manifestations of COVID-19: A rapid prospective nationwide consensus study in Spain with 375 cases. Br J Dermatol. 2020;183(1):71-77.

8. Marzano A, Cassano V, Genovese N, Moltrasio $G$ et al. Cutaneous manifestations in patients with COVID-19: A preliminary review of an emerging issue. $\mathrm{Br} J$ Dermatol. 2020.

9. Young S, Fernandez AP. Skin manifestations of COVID-19. Cleve Clin J Med. 2020.

10. Schadeva M, Gianiotti R, Shah M et al. Cutaneous manifestations of COVID-19: Report of three cases and a review of literature. J Dermatol Sci. 2020;98(2):75-81.

11. Feldman SR., Freeman EE. Coronavirus disease 2019 (COVID-19): Cutaneous manifestations and issues related to dermatologic care. Available at https://www. uptodate.com/contents/coronavirusdisease-2019-covid-19-cutaneousmanifestations-and-issues-related-todermatologic-care.

12. Fernandez-Nieto $D$, Ortega-Quijano $D$, Jimenez-Cauhe J, Burgos-Blasco P et al. Clinical and histological characterization of vesicular COVID-19 rashes: A prospective study in a tertiary care hospital. Clin Exp Dermatol. 2020:10.1111/ced.14277.

13. Le Cleach L, Dousset L, Assier H, Fourati S, Barbarot S, Boulard C et al; French Society of Dermatology. Most chilblains observed during the COVID-19 outbreak occur in patients who are negative for COVID-19 on polymerase chain reaction and serology testing. Br J Dermatol. 2020:10.1111/ bjd.19377.

14. Recalcati S, Barbagallo T, Frasin LA. Acral cutaneous lesions in the time of COVID-19. J Eur Acad Dermatol Venereol. 2020; 34(8):e346-e347.

15. Castelnovo L, Capelli F, Tamburello A et al. Symmetric cutaneous vasculitis in COVID-19 pneumonia. J Eur Acad Dermatol Venereol. 2020;34(8):e362-e363.

16. Cornejo-Garcia JA, Blanca-Lopez N, Dona I et al. Hypersensitivity Reactions to Non-Steroidal Anti-Inflammatory Drugs. Curr Pharm Des. 2016;22:6784-6802.

17. Kasemsarn P, Kulthanana K, Tuchinda P et al. Cutaneous reactions to non-steroidal anti-inflammatory drugs. J Drugs Dermatol. 2011;10(10):1160-7.

18. Tursen U, Tursen B, Lotti T. Cutaneous side-effects of the potential COVID-19 drugs. Dermatol Ther. 2020;e13476.

19. Leru PM. Drug allergies in primary care practice in Romania: A questionnaire-based survey. Allergy Asthma Clin Immunol. 2014; 10:16.

20. Leru PM, Deleanu DM. Romanian Allergology in the actual European context. Rom J Intern Med. 2015;53,2:111-117. 